\title{
A COMPARISON OF HAND-ASSISTED AND PURE LAPAROSCOPIC TECHNIQUES IN LIVE DONOR NEPHRECTOMY
}

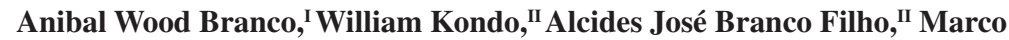

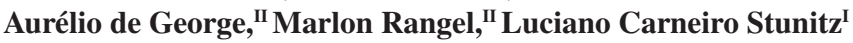 \\ doi: 10.1590/S1807-59322008000600015
}

Branco AW, Kondo W, Filho AJB, George MA, Rangel M, Stunitz LC. A comparison of hand-assisted and pure laparoscopic techniques in live donor nephrectomy. Clinics. 2008;63:795-800.

PURPOSE: To compare hand-assisted laparoscopic donor nephrectomy and pure laparoscopic live donor nephrectomy techniques in live donor nephrectomy.

METHODS: In this retrospective study, we included all patients submitted to hand-assisted laparoscopic donor nephrectomy and pure laparoscopic live donor nephrectomy between May 2002 and December 2007. The operative data and post-operative courses were reviewed. Information was collected on the operative time, warm ischemia time, estimated blood loss, intra-operative complications, time to first oral intake, length of hospital stay, and post-operative complications. The data were analyzed using Student's $t$-tests and Fisher exact tests as appropriate, with statistical significance defined as $p<0.05$.

RESULTS: The means of the operative duration, warm ischemia time and intra-operative bleeding were $83 \mathrm{~min}, 3.6 \mathrm{~min}$ and $130.9 \mathrm{cc}$, respectively, for hand-assisted laparoscopic donor nephrectomy, and $78.4 \mathrm{~min}, 2.5 \mathrm{~min}$ and $98.9 \mathrm{cc}$, respectively, for pure laparoscopic live donor nephrectomy ( $p=0.29, p<0.0001$ and $p=0.08$, respectively). Intra-operative complications occurred in $6 \%$ of patients submitted to hand-assisted laparoscopic donor nephrectomy and in $4.5 \%$ of those submitted to pure laparoscopic live donor nephrectomy $(p=0.68)$. Only one patient from each group required conversion to open surgery; one person receiving handassisted laparoscopic donor nephrectomy had bleeding and one person receiving pure laparoscopic live donor nephrectomy had low carbon dioxide levels during the warm ischemia period. Compared with patients receiving hand-assisted laparoscopic donor nephrectomy, patients submitted to pure laparoscopic live donor nephrectomy were able to take their first meal earlier (12.5 vs. 9.2 hours, $p=0.046)$, were discharged home sooner ( 2.8 vs. 1.4 days, $p<0.0001)$ and had fewer post-operative complications $(7.5 \%$ vs. $0.6 \%, p=0.04)$.

CONCLUSIONS: Pure laparoscopic live donor nephrectomy had some advantages over hand-assisted laparoscopic donor nephrectomy in terms of the warm ischemia time, time to first oral intake, length of hospital stay, and post-operative donor complications.

KEYWORDS: Laparoscopy; Nephrectomy; Kidney transplantation; Living donor; Hand-assisted.

\section{INTRODUCTION}

Since the introduction of laparoscopic donor nephrectomy in 1995 by Ratner et al., ${ }^{1}$ the procedure has gained in popularity because of the high graft quality and the inherent

\footnotetext{
${ }^{\text {I}}$ Department of Urology, Red Cross Hospital - Curitiba/PA, Brazil.

II General Surgery, Red Cross Hospital - Curitiba/PA, Brazil.

Email: williamkondo@yahoo.com

Tel.: 55413362.3863

Received for publication on August 12, 2008

Accepted for publication on September 15, 2008
}

advantages of laparoscopic surgery (e.g., decreased postoperative pain, decreased length of hospital stay, early recovery and return to work, and better cosmetic results). ${ }^{2-5}$ In addition, some centers have observed increases in the number of donations and have attributed these increases to the use of less invasive surgical procedures that are more acceptable to donors.

In 1998, hand-assisted laparoscopic nephrectomy was introduced that combined the laparoscopic technique with quicker and safer organ retrieval offered by the open access. ${ }^{6}$ By using the hand, complete mobilization of the 
colon is facilitated and the kidney and the aorta are easily exposed. In addition, tissue planes are more easily defined using the intraperitoneal hand for retraction. ${ }^{7}$ The surgical time is comparable with open nephrectomy and tends to decrease with a surgeon's learning curve. It can be safely performed without harm to the donor and without affecting the graft function..$^{8-10}$ This technique was perceived by most laparoscopic surgeons as easier to learn and more rapid to perform. However, some laparoscopic urologists considered it to be a learning step towards full laparoscopy. ${ }^{11}$

In experienced hands, both the pure and hand-assisted laparoscopic surgeries were considered safe and resulted in kidneys that functioned identically to those obtained following open nephrectomies. ${ }^{6,712,13}$ Comparisons between these two techniques have not demonstrated any statistically significant differences in analgesic requirements, hospital stays, or allograft function. Significantly shorter operation and warm ischemia times have been demonstrated in the hand-assisted laparoscopic groups compared with the standard laparoscopic groups. ${ }^{4,14,15}$

The aim of the present study was to compare the handassisted (HALDN) with the pure laparoscopic (PLLDN) technique in laparoscopic donor nephrectomies with respect to intra-operative and post-operative donor outcomes.

\section{METHODS}

We retrospectively examined the records of all patients submitted to pure laparoscopic or hand-assisted live donor nephrectomies at the Cruz Vermelha Hospital of Curitiba and the Pró-Rim Foundation of Joinville, between May 2002 and December 2007.

All potential donors had extensive medical, immunologic and psychological evaluations to confirm his/her suitability. The exams requested to delineate the anatomy of the kidney vasculature preoperatively were those usually performed for conventional renal donors, including digital angiography and intravenous pyelogram. The donor selection criteria for laparoscopic donor nephrectomy were identical to the standard criteria for open donor nephrectomy. For all donors, the left kidney was preferred because of the longer left renal vein. However, for a donor whose renal vascular anatomy was more favorable in the right kidney, the right kidney was selected. Similarly, for a donor whose right kidney was affected by a medical condition, the right kidney was also selected because we abided by the basic tenet that in choosing a donor's kidney for removal, the better kidney should remain in situ. ${ }^{10}$ All procedures were performed by the same urologist, who had experience in advanced laparoscopic surgery and no experience in open nephrectomy.
The operation data and post-operative courses were reviewed. Information on donor age, sex, and previous medical history were collected. The surgical data that was collected included operative time, warm ischemia time, estimated blood loss and intra-operative complications. Operative time was defined as the time from the initial skin incision to the final skin suture. ${ }^{16}$ Warm ischemia time was defined as the time elapsed from the application of haemostatic clips to the renal artery to the perfusion of the kidney with cold preservation fluid ${ }^{17}$. The post-operative variables included the time to first oral intake, the length of hospital stay, and post-operative complications.

All patients received a light mechanical bowel preparation $12 \mathrm{~h}$ before surgery and a single dose of cefazolin after anesthesic induction.

Procedures were performed using our previously described techniques:

1. Hand-assisted live donor nephrectomy, ${ }^{10}$ using the Lapdisc (Ethicon EndoSurgery Inc., USA) (Figure 1) or the Omniport (Advanced Surgical Concepts Ltd., Dublin, Ireland).

2. Pure laparoscopic live donor nephrectomy ${ }^{12}$ (Figure 2).

When necessary, maximization of the length of the right renal vein ${ }^{9}$ (Figures 3 and 4) or $\operatorname{artery}^{8}$ (Figure 5) was performed.

The data were analyzed using Student's $t$-tests and Fisher exact tests as appropriate, with statistical significance defined at $p<0.05$.

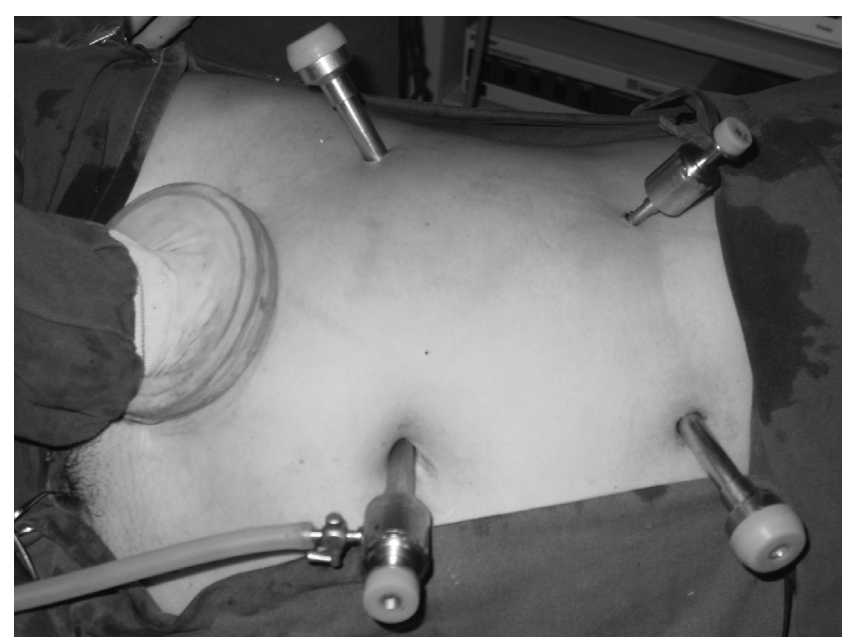

Figure 1 - Hand-assisted live donor nephrectomy using the Lapdisc

\section{RESULTS}

During the study period, 156 laparoscopic nephrectomies were performed, including 67 HALDN and 89 PLLDN. Table 1 shows the patient demographics and surgical outcomes in the HALDN and PLLDN groups. 


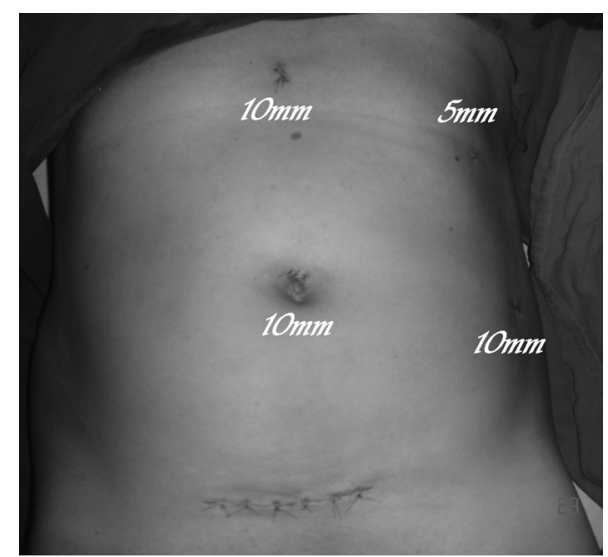

Figure 2 - Pure laparoscopic live donor nephrectomy using three $10 \mathrm{~mm}$ and one $5 \mathrm{~mm}$ ports - the kidney was retrieved from the abdominal cavity through a Pfannenstiel incision

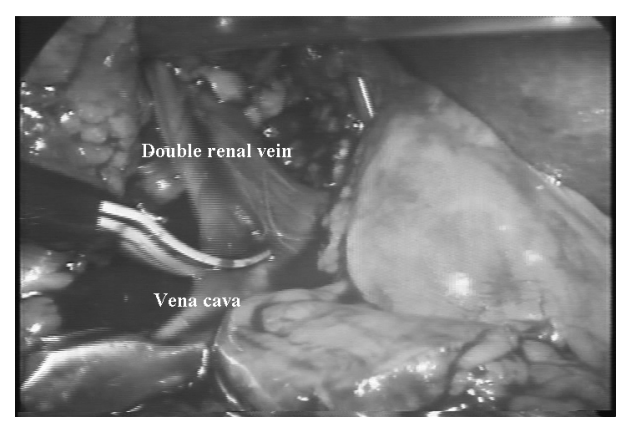

Figure 3 - Cutting the inferior vena cava to maximize the right renal vein length - maximizing the right renal vein length

Indications for right kidney harvesting included: multiple left renal vessels ( $n=37)$, right renal cyst $(n=5)$, fibromuscular dysplasia of the right renal artery $(\mathrm{n}=2)$, early bifurcation of the left renal artery $(n=2)$, right ureterocele $(n=1)$, right renal ptosis $(n=1)$, right-sided ureteropyelic junction stenosis

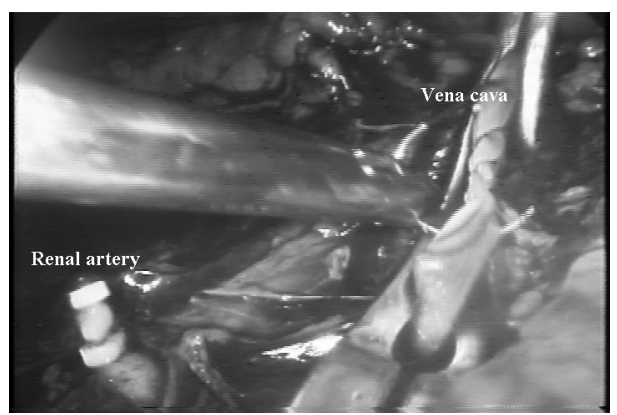

Figure 4 - Laparoscopic continuous running suture of the vena cava using 4-0 prolene

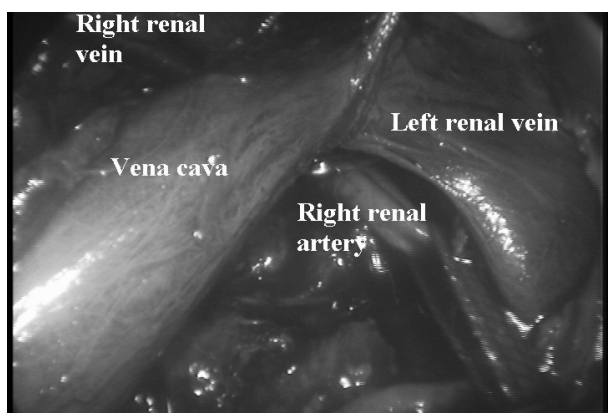

Figure 5 - The double right renal artery (arrow) was dissected up to its origin in the right lateral edge of the aorta - the vena cava and the renal artery were isolated using a tape

$(\mathrm{n}=1)$, right pelvic kidney $(\mathrm{n}=1)$ and left ureteral duplicity $(\mathrm{n}=1)$. In nine patients, we performed maximization of one of the right renal vessels, including four with maximization of the right renal vein and five with maximization of the right renal artery. All of these maximizations were performed because of early bifurcations of the vessels.

All nephrectomies were completed as scheduled, except for one HALDN (with bleeding) and one PLLDN (with low

Table 1 - Patient characteristics and complications during and after hand-assisted and pure laparoscopic live donor nephrectomy

\begin{tabular}{lccc}
\hline Characteristics/complications & HALDN $(\mathrm{n}=67)$ & PLLDN (n=89) & p value \\
Mean \pm SD (range) & $38 \pm 9,2$ & $38,9 \pm 10,4$ & 0.57 \\
\hline Age, years & $32 / 35$ & $44 / 45$ & 0.84 \\
Donor sex (M/F) & $43 / 24$ & $62 / 27$ & 0.47 \\
Side (Left/Right) & $83 \pm 28.8(45-180)$ & $78.4 \pm 25.3(33-130)$ & 0.29 \\
Operating time, min & $3.6 \pm 1.4(1.5-8.0)$ & $2.5 \pm 0.8(1.5-4.5)$ & $<0.0001$ \\
Warm ischemia time, min & $130.9 \pm 134.7(40-1000)$ & $98.9 \pm 74.8(40-350)$ & 0.08 \\
Estimated blood loss, cc & $4(6 \%)$ & $4(4.5 \%)$ & 0.68 \\
ID complications, $n(\%)$ & $1(1.5 \%)$ & $1(1.1 \%)$ & 0.84 \\
Conversion, $n(\%)$ & $12.5 \pm 15.2$ & $9.2 \pm 2.8$ & 0.046 \\
First oral intake, hours & $2.8 \pm 1(2-7)$ & $1.4 \pm 0.7(1-3)$ & $<0.0001$ \\
Hospital stay, days & $5(7.5 \%)$ & $1(0.6 \%)$ & 0.04 \\
PD complications, $n(\%)$ & & \\
\hline
\end{tabular}

$\mathrm{ID}=$ Intraoperative donor; $\mathrm{PD}=$ Postoperative donor 
carbon dioxide during the warm ischemia time) that required conversion to open surgery. The mean (range) kidney warm ischemia time was $3.6(1.5-8.0) \mathrm{min}$ for the HALDN and 2.5 (1.5-4.5) min for the PLLDN $(\mathrm{p}<0.0001)$. The mean operating time was 83 (45-180) $\mathrm{min}$ in the HALDN group and $78.4(33-130)$ min in the PLLDN group $(p=0.29)$, and the mean intra-operative bleeding was 130.9 (40-1000) cc in the HALDN group and 98.9 (40-350) cc in the PLLDN group $(\mathrm{p}=0.08)$.

Only one patient required blood transfusion during surgery; this person was in the HALDN group. The complications are listed in Table 2.

Table 2 - Complications

\begin{tabular}{lcc}
\hline Intraoperative complications & HALDN $(\mathrm{n}=4)$ & PLLDN $(\mathrm{n}=4)$ \\
\hline Major vascular injury & 2 (one conversion) & 1 \\
Renal vein & 1 & 1 \\
Vena cava & - & 1 \\
Renal artery & 1 & - \\
Malfunction of titanium clip & - & 1 \\
Gallbladder perforation & HALDN (n=5) & PLLDN $(\mathrm{n}=1)$ \\
Postoperative complications & 1 & 1 \\
Surgical site hematoma & 1 & - \\
Coagulopathy and peri-renal & 1 & - \\
hematoma & 2 & - \\
Peripancreatic fluid collection & & \\
Ileus & &
\end{tabular}

The frequency of intra-operative donor complications was $6 \%$ in the HALDN group and $4.5 \%$ in the PLLDN group (Table 2). Six major vascular bleedings occurred (three renal veins, two vena cavas, and one renal artery) and all but one were laparoscopically controlled. The only patient that required conversion to open surgery had an intra-operative bleeding of $1000 \mathrm{cc}$ and needed blood transfusion. One gallbladder perforation during a Veress needle placement in the right subcostal area was observed and was laparoscopically managed. One malfunction of the titanium clip placed on the renal artery was observed with the hand-assisted technique. The clip sectioned one part of the artery and a laparoscopic suture was necessary.

The frequency of post-operative donor complications was $7.5 \%$ in the HALDN group and $0.6 \%$ in the PLLDN group (Table 2). Two patients who had HALDN required re-operation due to peri-pancreactic fluid collection and a peri-renal hematoma. The patient with peri-pancreactic fluid collection probably developed this complication because of manipulation of the pancreatic fascia during dissection; the patient underwent laparoscopic drainage with a good post-operative course. The other patient had an inguinal hematoma due to femoral bleeding, which is a complication of the angiography, and subsequent coagulopathy because of the use of clotting factors. Although the laparoscopic nephrectomy was performed without difficulty, this patient presented with a peri-renal hematoma on the third postoperative day because of the coagulopathy and required laparoscopic drainage and a red blood cell transfusion. Both cases of prolonged ileus resolved spontaneously after NPO (nothing by mouth) for 4 days and were discharged on the seventh post-operative day.

The length of hospital stay (LOS) was evaluated for the two groups. We found that the PLLDN technique was associated with markedly reduced hospital LOS compared with donors undergoing HALDN (2.8 vs. 1.4; $p<0.0001$ ) (Table 2). Within 24 hours of surgery, 63 patients in the PLLDN group were discharged while none were discharged in the HALDN group.

\section{DISCUSSION}

Live donor kidney transplantation is the treatment of choice for end-stage renal failure. Living donors are healthy individuals who take the risk of a major operation to donate one of their kidneys. If a donor's post-operative quality of life in terms of morbidity and mortality could be improved, more people may volunteer for kidney donations ${ }^{3}$. A major improvement was achieved by the introduction in 1995 of the laparoscopic live donor nephrectomy ${ }^{1}$, which was shown to offer a graft with a quality that was high and similar to that of grafts obtained with open nephrectomy. HALDN is a modification of the laparoscopic technique that may carry a number of theoretical advantages including a greater margin of safety, a shorter learning curve and a potential reduction in operative time and procedure $\cos ^{18-20}$ while maintaining high graft quality.

Few studies have compared the outcomes of PLLDN and HALDN. The first meta-analysis comparing both techniques ${ }^{3}$ showed that the hand-assisted procedure 1) offered a quicker method of kidney retrieval as reflected by the shorter total operating and warm ischemia times, 2) maintained safety (as evidenced by a similar number of donor complications), 3 ) offered good renal graft quality as demonstrated by the posttransplant creatinine levels and 4) was associated with lower estimated blood loss, an important parameter to indicate the level of difficulty of the procedure. Explanations for these advantages include a gain in spatial orientation for the surgeon with the hand-assisted method and better bleeding control achieved by direct digital manipulation.

In our experience, the total operating time was shorter with the PLLDN than with HALDN (78.4 vs. 83 minutes), 
but the difference was not statistically significant $(p=0.29)$. Estimated blood loss was also similar in the two groups (98.9 vs. $130.9 \mathrm{cc}, p=0.08$ ). Warm ischemia time was significantly shorter with PLLDN compared with HALDN (2.5 vs. 3.6 min, $p<0.0001)$. In our opinion, these differences can be attributed to the fact that the PLLDNs were performed after the initial learning curve on HALDNs. Initially, all procedures were performed using hand assistance (from the $1^{\text {st }}$ to the $67^{\text {th }}$ donor). Subsequently, we have been performing nephrectomies only using the pure laparoscopic approach.

Independent of the technique used, donor complications in laparoscopic donor nephrectomies seem to be declining, and the frequency of complications decrease with the increasing experience of the surgeons. In the meta-analysis by Kokkinos et al. ${ }^{3}$, the hand-assisted group had less intraand post-operative complications than the pure laparoscopic group, but the difference was not statistically significant. Most of the intra-operative complications were vessel injuries (five for the HALDN and five for the PLLDN group). Furthermore, the HALDN group also had one bowel injury, whereas the PLLDN group had three splenic injuries, one diaphragmatic tear, two renal torsions, and two cases of equipment failure (endoscopic vascular stapler failed to divide the renal vein, retrieval bag failed to trap the kidney). Conversion to the open procedure was less frequent with HALDN patients than with PLLDN patients (2.6\% vs. $4.1 \%$ ), but the difference was not statistically significant. In a recent series from the University of Maryland ${ }^{21}$ among 738 laparoscopic donor nephrectomies, 15 major complications were reported, including 13 vascular injuries and two bowel injuries. In the present study, there were no significant differences in intra-operative complications between both groups. We observed four intra-operative complications in the HALDN group, including three vessel injuries (two renal veins and one vena cava) and one malfunction of the titanium clip placed on the renal artery. We observed four intra-operative complications in the PLLDN group (one renal vein, one renal artery, one vena cava, and one gallbladder perforation by the Veress needle). All but one of the vascular injuries were laparoscopically managed. The one patient who needed conversion to open surgery and a blood transfusion due to intra-operative bleeding was in the hand-assisted technique group. In previous studies, the conversion to open surgery from laparoscopic donor nephrectomies was $1.6-13 \%,,^{14,21,22}$ but such conversion was required in only two patients $(1.3 \%)$ in the present study. The other donor that required conversion was treated with the pure laparoscopic approach. Since the carbon dioxide gas finished just during the warm ischemia time, we had to convert to open surgery to retrieve the specimen from the abdominal cavity.

Post-operative complications were more frequent in the HALDN group compared with the PLLDN group ( $7.5 \%$ vs. $0.6 \%, p=0.04)$. Both cases of prolonged ileus occurred in the HALDN group and resolved spontaneously, but these patients required 7 days of hospitalization. One case of abdominal wall hematoma was observed in each group. Both patients were drained and good post-operative courses. Two patients required re-operation, one for peri-pancreatic fluid collection and the other for a peri-renal hematoma. The procedures were performed by laparoscopy and, after the second procedure, post-operative courses were uneventful.

Velidedeoglu et al..$^{20}$ compared the open, laparoscopic and hand-assisted approaches to live-donor nephrectomy. Their data revealed that both of the minimally invasive techniques could be applied with excellent results and that reductions in donors' LOS were observed due to the accelerated postoperative recovery. In a similar comparison study, El-Galley et al. ${ }^{2}$ observed a post-operative hospitalization of $2 \pm 2$ days for the laparoscopic techniques and $3 \pm 2$ days for the open approach $(p=0.01)$. In the beginning of surgeons' experience with the laparoscopic techniques, patients were discharged on the third post-operative day. However, after the first 20 patients, probably due to the shortened operative time, the majority of full laparoscopic patients were discharged on the second post-operative day. Kuo et al. reported full laparoscopic nephrectomies with only a 23-hour hospital stay $^{5}$. Their findings were similar to our experience. After our initial learning curve on HALDN, we were able to discharge 63 patients submitted to PLLDN during the first post-operative day.

\section{CONCLUSION}

The experience of the surgeon is an important variable that determines the result of a surgical procedure and should be considered when determining the most appropriate treatment. Based on our data, se suggest that once the surgeons' learning curves are reached, PLLDN seems to have some advantages compared with HALDN in terms of warm ischemia time, time to first oral intake, length of hospital stay, and post-operative donor complications. Future research should be conducted in large, multi-center, randomized controlled trials with defined follow-up periods, taking into consideration the experience of the surgeon, the learning curve of the procedure, and the comorbidity of the patient. 


\section{REFERENCES}

1. Ratner LE, Ciseck LJ, Moore RG, Cigarroa FG, Kaufman HS, Kavoussi LR. Laparoscopic live donor nephrectomy. Transplantation. 1995;60:1047-9.

2. El-Galley R, Hood N, Young CJ, Deierhoi M, Urban DA. Donor nephrectomy: A comparison of techniques and results of open, hand assisted and full laparoscopic nephrectomy. J Urol. 2004;171:40-3.

3. Kokkinos C, Nanidis T, Antcliffe D, Darzi AW, Tekkis P, Papalois V. Comparison of laparoscopic versus hand-assisted live donor nephrectomy. Transplantation. 2007;83:41-7.

4. Flowers JL, Jacobs S, Cho E, Morton A, Rosenberger WF, Evans D, et al. Comparison of open and laparoscopic live donor nephrectomy. Ann Surg. 1997;226:b483-9.

5. Kuo PC, Johnson LB, Sitzmann JV. Laparoscopic donor nephrectomy with a 23-hour stay: a new standard for transplantation surgery. Ann Surg. 2000;231:772-9.

6. Wolf JS Jr, Tchetgen MB, Merion RM. Hand-assisted laparoscopic live donor nephrectomy. Urology. 1998;52:885-7.

7. Slakey DP, Wood JC, Hender D, Thomas R, Cheng S. Laparoscopic living donor nephrectomy: advantages of the hand-assisted method. Transplantation. 1999;68:581-3.

8. Branco AW, Branco Filho AJ, Kondo W, George MA, Rangel M, Noda RW. Alongamento da artéria renal direita na nefrectomia vídeo-assistida em doador renal. Rev Bras Videocir. 2005;3:3-8.

9. Branco AW, Branco Filho AJ, Kondo W, George MA, Carvalho RM, Maciel RF. Maximizing the right renal vein length in laparoscopic live donor nephrectomy. Int Braz J Urol. 2004;30:416-9.

10. Branco AW, Branco Filho AJ, Kondo W, George MA, Maciel RF, Garcia MJ. Hand-assisted right laparoscopic live donor nephrectomy. Int Braz J Urol. 2005;31:421-30.

11. Gill IS. Hand-assisted laparoscopy: con. Urology. 2001;58:313-7.

12. Branco AW, Kondo W, Branco Filho AJ, Deboni L, Guterres J, Silva A. Nefrectomia laparoscópica em doador vivo: análise retrospectiva de 151 casos. Rev Bras Videocir. 2007; 5:19-26.
13. Branco AW, Branco Filho AJ, Kondo W. Laparoscopic live donor nephrectomy in patients surgically treated for morbid obesity. International Braz J Urol. 2007;33:377-9.

14. Jacobs SC, Cho E, Dunkin BJ, Flowers JL, Schweitzer E, Cangro C, et al. Laparoscopic live donor nephrectomy: the University of Maryland 3-year experience. J Urol. 2000; 164:1494-9.

15. Turk IA, Deger S, Davis JW, Giesing M, Fabrizio MD, Schönberger B, et al. Laparoscopic live donor right nephrectomy: a new technique with preservation of vascular length. J Urol. 2002;167:630-3.

16. Simforoosh N, Basiri A, Tabibi A, Shakhssalim N, Hosseini Moghaddam SM. Comparison of laparoscopic and open donor nephrectomy: a randomized controlled trial. BJU Int. 2005;95:851-5.

17. Boorjian S, Munver R, Sosa RE, Del Pizzo JJ. Right laparoscopic live donor nephrectomy: a single institution experience. Transplantation. 2004;77:437-40.

18. Colombo JR Jr, Haber GP, Aron M, Cocuzza M, Colombo R, Kaouk J, Gill IS. Oncological outcomes of laparoscopic radical nephrectomy for renal cancer. Clinics. 2007;62:251-6

19. Lucon AM, Coelho RF, Chambô JL, Mitre AI, Praxedes JN, Srougi M. Hand-assisted laparoscopic right nephrectomy and autotransplantation for treatment of renovascular hypertension. Clinics. 2007;62:367-70.

20. Velidedeoglu E, Williams N, Brayman KL, Desai NM, Campos L, Palanjian M, et al. Comparison of open, laparoscopic, and hand-assisted approaches to live-donor nephrectomy. Transplantation. 2002;4:16972 .

21. Jacobs SC, Cho E, Foster C, Liao P, Bartlett ST. Laparoscopic donor nephrectomy: the University of Maryland 6-year experience. J Urol. 2004; $171: 47-51$

22. Brown SL, Biehl TR, Rawlins MC, Hefty TR. Laparoscopic live donor nephrectomy: a comparison with the conventional open approach. J Urol. 2001;165:766-9. 